\title{
Frederick H. Hayes
}

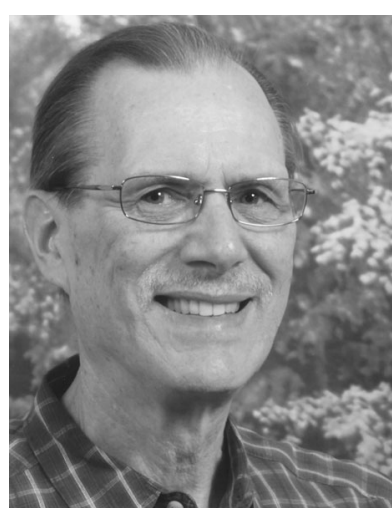

John E. Morral

It is with great pleasure that the Journal of Phase Equilibria and Diffusion hosts this special issue in honor of Fred Hayes. The issue was edited by Andy Watson who solicited papers and supervised the reviewing process. We are grateful for his generous work and for the opportunity to publish these fine articles.

Jack Smith, our previous and long time Editor of the journal, remembers Fred well. He saw him at CALPHAD meetings and was quick to recognize his exceptional ability. When approval was obtained to appoint Associate Editors to the journal, Jack named Fred to the inaugural group. That was in 1990 when the journal was still "the Bulletin of Alloy Phase Diagrams." Mary Anne Fleming, the ASM Senior Content Developer of Journals, worked with Fred during his tenure with the Journal and remembers his congenial personality and enjoyed working with him.

Over the years Fred served the journal by guiding numerous manuscripts through the review process. In addition he wrote editorials that can be found in the June 1992 and 1994, April 1996 and 1998, and June 2004 issues. His editorials were often focused on current trends and how they might affect our field in the future. For example in 1992 he saw that financial pressures in Great Britain would lead to more collaborative efforts between universities at home and abroad. In 1994 he foresaw the need for more communication between phase diagram calculation and experimental specialists of all types. That would create greater understanding of binary as well as multicomponent systems. Communication between specialists is more common now, especially at meetings and within funded programs.

In 1996 and in 2004 he saw the increased use of computers in phase diagram work as a good trend, but the reduction of courses and research on thermodynamics in universities as a bad trend. Unfortunately the bad trend regarding thermodynamics has continued, as discussed recently by Herbert Ipser in his June 2012 editorial.

In addition to friends and colleagues, Fred will be remembered by those who have been influenced by his scientific legacy. One example occurred three years ago. A PhD student came to my office to discuss a project. The aim was to homogenize $\mathrm{MgB}_{2}$ in order to improve its superconductivity properties. As part of the project he intended to determine the $\mathrm{MgB}_{2}$ incongruent melting temperature using a thermal analysis suggested in 1942 by Cyril Stanley Smith. The method is known as the Smith Thermal Analysis or STA. Unlike conventional DTA, the STA method maintains a constant rate of heat flow between the specimen and the surroundings, which is superior to DTA at detecting invariant reactions. However it appeared from the literature that no one had used this method until the $1980 \mathrm{~s}$. The student wondered if I knew about this method and would recommend it. When I learned from the student that Fred Hayes had been a pioneer in developing this experimental method and in articulating its advantages and disadvantages, I recommend it at once. Fred's involvement was all I needed to know, because, just like Jack Smith's experience, I had met Fred Hayes at CALPHAD meetings and was quick to recognize his exceptional ability.

John E. Morral Emeritus Professor, The Ohio State University, Columbus, $\mathrm{OH}$, USA E-mail: jemorral@gmail.com 